\title{
ANNOTATION
}

\section{Association for the Prevention of Blindness in Bengal}

The Ninth Annual Report of the Association for the Prevention of Blindness in Bengal, 1938-1939, has just reached us. It shows how much has already been accomplished in a short time and makes most interesting reading. The common underlying causes of blindness in Bengal are apathy, ignorance and poverty. With the limited funds at its disposal the Association is obviously doing magnificent work and great credit must be given to the Committee and especially to its Hon. Secretaries, Lieut.-Col. E. O'G. Kirwan and Dr. S. K. Mukerjee for the immense amount of time and trouble they have taken and are taking. The number of totally blind in India is approximately one million, and the number of partially blind in India is approximately three million. There are 37,000 totally blind and 111,000 partially blind in Bengal. Sixty per cent. of blindness is preventable and universal vaccination would prevent more blindness than all the eye hospitals in India could cure.

Egypt with its population of $15,000,000$ has 17 travelling eye dispensaries; India with $350,000,000$ population has only two travelling eye dispensaries. The Jubilee Travelling Eye Dispensary has treated 42,761 cases in 751 working days. The Second Travelling Eye Dispensary has treated 36,396 cases in 400 working days. And these two dispensaries have so far covered only a small area. Five dispensaries are needed for the five divisions of Bengal. It is heartening to learn that the Government has sanctioned a grant for the ensuing year which will enable the Committee to put two more travelling dispensaries into commission. During the year under review the Committee has arranged for the eye examination of children in schools and orphanages in Bengal.

The propaganda work includes lectures, posters, films, publications, exhibitions, radio talks and newspaper articles with other miscellaneous items.

Some of the posters published by the Association are reproduced in the report. They include one on septic teeth; one on the essential foods to prevent keratomalacia; one on the enemies of childrens' eyes, viz.: sore eyes at birth, smallpox, keratomalacia and inherited syphilis ; and one on the danger of leaning out of carriage window's on trains without wearing goggles.

Other illustrations show some of the crowds of patients waiting for treatment at the travelling eye dispensaries. Appendices contain among other items, a statement of accounts for the year, the annual budget for a travelling eye dispensary, a list of schools where lectures (Red Cross) and demonstrations have been given and the yearly report of the two travelling eye dispensaries. 
It is obvious that the Association is doing splendid work. Finance is, of course, the most urgent problem; with increased resources we may expect that the Association will be able to do much towards combating a serious menace to the prosperity of the Bengal Presidency, and also the whole of India.

\section{ABSTRACTS}

\section{MISCELLANEOUS}

(1) Blatt, Nicholas (Bucharest).-Selection of flying personnel. (Sélectionnement des aviateurs, au point de vue de leur organe visuel). Rev. de Service de santé militaire. March, 1940.

(1) Good sight is essential to all the members of any flying corps but there are many points which are equally important, besides central acuity of vision. Blatt in this paper explains in what direction their importance lies, and how the candidate must be examined to ensure that no unsuitable man gets through.

A number of functions of the eye must be investigated; the central acuity must be normal or very nearly so; in most countries it is usual to exclude all who wear glasses, but it seems unnecessary in the author's opinion to draw the line so rigorously. He would allow low hypermetropia, so long as the vision was perfect with the correction, which should be worn always. A full field is necessary; this must be taken on a perimeter. The fundus must be examined and be normal. Light sense must be normal; a man with deficient light sense is at a grave disadvantage in a bad light and is almost a blind man. It is not easy to test the light sense ; a fair judgment may be made by reducing the light reaching the eye by dark glasses and comparing the vision of the candidate with that of the examiner; if the light sense of the latter is good and the findings of the candidate agree, the candidate may be assumed to have normal sense.

Muscle balance must be good; a low exophoria is admissible but esophoria, even of low degree, may give rise to errors of judgment in estimating distances; it is therefore a bar to acceptance. Estimation of distance and stereoscopic vision must be good. Colour vision must be good; the author holds that the examination both of colour sense and central acuity, should be made out of doors, if possible under conditions of flying. Lastly, the mental agility must be examined; the pilot must be quick to receive and to interpret stimuli and to act at once on the information thus attained.

HAROLD GRIMSDALE. 